\title{
Una edición crítica de la quiná sefardí de La destrucción del Templo
}

Paloma DÍAZ-MAS

CSIC, Madrid

Es bien sabido que en la celebración religiosa de Tiš á beab, en la que se conmemora la destrucción del Templo, los sefardíes solían entonar -además de las quinot en hebreo de la liturgia sinagogal- endechas en lengua vulgar, que podían ser versiones ladinadas de las quinot hebreas ${ }^{1}$, quinot en lengua sefardí ${ }^{2}$, e incluso endechas por la muerte de una persona particular ${ }^{3}$ o romances tradicionales cuya temática se percibía como luctuosa ${ }^{4}$.

Entre las quinot en judeoespañol se encuentra la que suele titularse La destrucción del Templo: un lamento por la toma de Jerusalén, que se inicia con una invocación de la Casa Santa («El Bet hamicdáš honrado»), recordando su hermosa arquitectura, su valor

\footnotetext{
${ }^{1}$ Algunas quinot ladinadas (varias de ellas enfrentadas con su texto hebreo) incluye Isaac LÉVY, Antología de Liturgia Judeo-Española (Jerusalén s.a.) vol. IV, págs. 199, 292 y 299; vol. VIII, págs. 67-69 y 150-157; y vol. IX (Jerusalén 1977) págs. 252 y 312-318. Estudia una de las más difundidas Herman P. SALOMON, «Hispanic Liturgy Among Western Sephardim», American Sephardi II (1968) págs. 49-58

${ }^{2}$ El trabajo fundamental es el de Iacob M. HASSÁN y Elena Romero, «Quinot paralitúrgicas: Edición y variantes», Estudios Sefardíes 1 (1978) págs. 3-57; más datos y textos en Paloma DíAZ-MAS, Temas y tópicos en la poesía luctuosa sefardí (Madrid 1982) págs. 11-12 y 108-221.

${ }^{3}$ P. DÍAZ-MAS, Temas y tópicos..., págs. 8-10 y 26-80.

${ }^{4}$ P. DíAZ-MAS, Temas y tópicos..., págs. 12-13 y 222-302. Para las causas que pudieron motivar el uso de un romance como canto luctuoso, puede verse Paloma DíAZ-MAS, «Romances sefardíes de endechar», en Actas de las Jornadas de Estudios Sefardies de 1980, ed. A. ViudAs CAMARASA (Cáceres 1981) págs. 99-105.
}

Sefarad 62 (2002) págs. 275-308

(c) CSIC

ISSN 037-0894 
de símbolo espiritual y el antiguo esplendor del culto, que contrastan con su estado ruinoso actual, con la profanación de que ha sido objeto el santuario y las vejaciones padecidas por los ministros del culto y por la población jerosolimitana en general. El poema está compuesto en cuartetas zejelescas y a lo largo de él encontramos motivos que evocan las Lamentaciones jeremíacas o los Salmos, junto con recursos característicos de la poesía luctuosa.

\section{TESTIMONIOS ALJAMIADOS Y EDICIONES MODERNAS}

El texto nos ha llegado en tres fuentes aljamiadas: dos libritos impresos y un manuscrito.

1) El librito Cará 'alay mo éd (heb. lit. 'convocó contra mí una asamblea', cita parcial de Lamentaciones 1.15), del que hay un ejemplar en la Biblioteca del Seminario Etz Haim de Amsterdam y otro en el Instituto Ben Zvi de Jerusalén. El del Seminario Etz Hayim conserva su portada, en la que se indica que está impreso en Venecia en el año 5513 (=1753) «Nella Stamparia Bragadina»; mientras que el del Instituto Ben Zvi carece de la hoja de portada y aparece encuadernado en un volumen de Séder arbá 'ta aniyot u 'orden de los cuatro ayunos' (el quinto de los cuales es Tiš 'á beab), impreso también en la misma imprenta Bragadina en 1751; yo he podido manejar sendas reproducciones de la Biblioteca de Estudios Sefardíes del CSIC. En adelante, nos referimos a este testimonio como $C$.

Es el número 14 del catálogo bibliográfico de coplas sefardíes ${ }^{5}$, donde aparecen los dos ejemplares como pertenecientes a la misma edición. Sin embargo, aunque los dos libritos presentan la misma composición, idéntica tipografía y son iguales a plana y renglón, en el del Seminario Etz Hayim el texto de la quiná (h. 2r) va preceקרא עלי מועד / קינה / בלשון ספרד dido del epígrafe en letra cuadrada

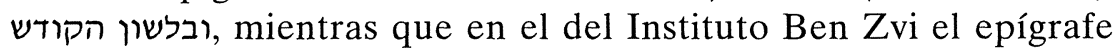
reza קרא עלי מועד / בלשון ספרד ובלשון הקודש (falta, por tanto, la segunda línea, con la palabra קינה) (קלער); lo cual parece indicar que se trata -si no de ediciones distintas-, por lo menos de emisiones diferentes de una misma edición.

5 Elena Romero, con la colaboración de Iacob M. HASSÁn y Leonor CARRACEDO, Bibliografía analítica de ediciones de coplas sefardíes (Madrid 1992). 
El texto de nuestra endecha ocupa la práctica totalidad del libro (hs. 2r-10r); aparece impreso en letra cuadrada y vocalizado con puntuación masorética, lo cual no es ciertamente muy frecuente en impresos judeoespañoles, donde resulta más usual el empleo de la letra raší sin puntos; probablemente en la elección de la letra cuadrada vocalizada hubo de influir la consideración de texto litúrgico (como demuestra el prólogo que le acompaña: véase más abajo) y el hecho de que a cada estrofa siga su traducción (a veces, muy libre) al hebreo. Sobre las circunstancias en que se realizó esa traducción volveremos más adelante.

2) La segunda fuente es un librico en letra raší sin portada, en cuyo folio se lee Quinot leTb ('endechas para T[iš 'á] b[eab]'), impreso en Jerusalén sin fecha (pero ha de ser de ca. 1900, según se indica en el catálogo bibliográfico de coplas antes citado: núm. 179). Se conserva en la Jewish National University Library de Jerusalén; he manejado la reproducción de la Biblioteca de Estudios Sefardíes del CSIC. En adelante, lo denominamos $Q$.

Nuestro texto (en hs. $7 \mathrm{v}-8 \mathrm{v}$ ) va acompañado de sendas versiones de otras cinco quinot ${ }^{6}$.

3) Otro texto nos ha llegado en un manuscrito aljamiado sin título, que se conserva en la biblioteca del Instituto Ben Zvi de Jerusalén ${ }^{7}$, copiado en Oriente a partir de 1887 por un tal Šemuel Alḥadef; de él hay también reproducción en la Biblioteca de Estudios Sefardíes del CSIC. En adelante nos referimos a él como $M s$.

Nuestro poema ocupa las hs. $21 \mathrm{v}-23 \mathrm{r}$ y le acompañan versiones de varias quinot en hebreo, ladinadas y en judeoespañol ${ }^{8}$. El nombre del propietario y seguramente compilador y la fecha se leen en un explicit de 24v: «hayom lehodeš ab 5 šenat 5647. Dito defter es de s. Šemuel Alhadef b. Peraia Alhadef» ("hoy [es] día 5 del mes de ab del año 5647 [1887]. Este cuaderno es de s[eñor] Šemuel Alhadef b[en 'hijo de'] Peraia Alhadef'). En hojas posteriores se encuentran otras fechas: en $34 \mathrm{r} \ll 652 »$ [1892] y en $38 \mathrm{r}$ una serie de

\footnotetext{
${ }^{6}$ Son las cinco editadas por I. M. HASSÁn y E. ROMERO, «Quinot...», citado en nota 2.

${ }^{7}$ Describren el manuscrito I. M. HASSÁN y E. ROMERO, «Quinot...», pág. 12.

${ }^{8}$ En total, contiene una veintena de quinot, de las cuales seis son en hebreo, nueve ladinadas y cuatro en judeoespañol (estas últimas son de las que editan HASSÁN y ROMERO, «Quinot...»).
} 
cómputos numéricos entre los cuales aparece la cifra «5684» [1924]. El manuscrito, por tanto, debió de copiarse entre 1887 y 1924 (o despúes), pero el texto de La destrucción del Templo se encuentra en la parte primera y más antigua y acaba precisamente en la h. 23, previa a la 24 en la que se indica la fecha de 1887.

4) Ediciones modernas: nuestra quiná ha recibido ya alguna atención por parte de los estudiosos: M. GRÜNBAUM publicó una transcripción parcial del texto de Cará 'alay mo ed ${ }^{9}$; y, más recientemente, Elena ROMERO ha publicado la versión completa de ese mismo librico (corrigiendo algunas lecturas con las del ms. Alhadef), con un breve comentario y notas, en su antología de coplas ${ }^{10}$. No existe, sin embargo, ninguna edición crítica basada en las tres versiones aljamiadas.

\section{PARA UNA EDICIÓN DE LA QUINÁ DE LA DESTRUCCIÓN DEL TEMPLO}

El primer problema que se plantea al abordar una edición crítica de la quiná judeoespañola de La destrucción del Templo son las notables diferencias que el texto presenta en los distintos testimonios textuales que han llegado hasta nosotros.

1) El testimonio de $C$, además de más antiguo, es el más cabal de los tres. Consta de treinta y tres estrofas (incluida la inicial), que se presentan tipográficamente bien diferenciadas: numeradas con letras hebreas, con amplios espacios entre una y otra y con partición de versos.

Tiene además la ventaja de ser un texto vocalizado, lo cual disipa ambigüedades en la lectura de las vocales. Por lo que se refiere al consonantismo resulta, sin embargo, más ambiguo que los textos más modernos, ya que, como es sabido, el sistema gráfico aljamiado sefardí del siglo XVIII utiliza el mismo signo ( $(v)$ para la prepalatal fricativa sorda y para la sibilante sorda (veáse nuestra nota a $7 \mathrm{~d}$ en la edición del texto); este testimonio presenta también cierta vacilación entre el uso de $ב$ y de $ו$ para la labial fricativa; y en algún caso la bilabial oclusiva sorda $/ \mathrm{p} /$ se indica erróneamente con

${ }^{9}$ Judisch-spanische Chrestomathie (Frankfurt an Main 1896) págs. 72-74.

${ }^{10}$ Coplas sefardíes: Primera selección (Córdoba 1988) págs. 91-98. 
פ con rafé, signo que corresponde a la labiodental fricativa /f/ (así frofondino por profondino en $2 \mathrm{~d}$; faseado por paseado en $3 \mathrm{~d}$ ).

Tras cada una de las estrofas -y tal y como anuncia el epígrafe - pre incluye su traducción al hebreo, impresa asimismo en letra cuadrada (de cuerpo algo mayor) con puntos vocálicos; sobre las circunstancias en que se produjo este traslado da noticia el prólogo en hebreo que abre el librito en el ejemplar del Seminario Etz Hayim (h. 1v) ${ }^{11}$ :

Cuántas y cuántas generaciones han pasado sobre esta elegía hermosa y pura en lengua sefardí, sin que se le hubiera ocurrido a ninguno de nuestro pueblo explicarla y traducirla a la lengua santa, la que despierta nuestro corazón de hijos de Israel hacia nuestro Padre que está en los cielos y la de la misericordia de nuestro Dios, Dios de Israel, más que cualquier otra lengua del mundo, según su nombre. Y dado que en Levante acostumbran en su tiempo oportuno a decirla en voz alta en las sinagogas y también en años pasados acostumbraban igualmente a decirla en las santas sinagogas sefardíes y levantinas, que Dios guarde, de la ciudad de Venecia, y no he sabido por qué se han apartado de ella; un hombre grande la compuso, puesto que está basada también en dichos de nuestros rabinos. Por todo ello se ha sentido dispuesto mi espíritu, según he dicho, y con ayuda de Dios he sido capaz de elaborarla según mi corto entender, máxime cuando no comprendo claramente la lengua sefardí. Pague Dios su salario a nuestro honorable rabino David Maestro, que Dios guarde, que me la hizo entender en lengua italiana. Y tú, lector amable, tómala como está, hasta donde alcanza mi mano, del mismo modo que mi intención está en los cielos para darle gracia a muchos leyéndola como tal en su momento. Pues Dios nos da gracia al escuchar de nuestra boca el recuerdo de la destrucción del Templo y cómo rezamos por la redención, tal como está formulado en todas nuestras oraciones. Ojalá escuche Dios nuestra aflicción y la trueque en alegría y gozo.

La cita, pese a su estilo retórico, nos proporciona interesante información acerca de diversas cuestiones: la difusión y uso del poema en las comunidades sefardíes de Oriente y en Venecia, su

\footnotetext{
${ }^{11}$ Lo traduce parcialmente E. Romero, Coplas sefardies..., pág. 92; agradezco a Iacob M. Hassán el haberme proporcionado traducción completa de este prólogo y de la versión hebrea que acompaña al texto judeoespañol, así como su ayuda para la resolución de algunos hebraísmos y la consulta de fuentes bibliográficas hebreas.
} 
antigüedad ${ }^{12}$ y posibles orígenes; pero lo que aquí nos interesa de momento es la declaración de que la versión hebrea impresa junto con la judeoespañola es, no ya una traducción, sino una traducción de una traducción, hecha por alguien que no sabía bien judeoespañol y quizás basándose en una explicación oral más que en un texto escrito (nótese que no dice que David Maestro le proporcionase un traslado al italiano, sino שהבינה 'que me la hizo entender': ¿oralmente?). De ahí que la versión hebrea no sea demasiado fiable para aclarar los pasajes confusos del texto judeoespañol, aunque ocasionalmente hayamos recurrido a ella porque indica, al menos, cómo entendía el poema el traductor (véanse nuestras notas a vv. 10a-b, 11c, 13b, 13c, 17a, 17d, 18b, 30a, 31b-d).

2) La versión de $Q$ tiene diecisiete estrofas (incluida la inicial, que aquí es sólo un pareado) y se nos presenta escrita a renglón seguido, en letra raší, precedida del epígrafe «Quiná sobre el Bet hamicdáš». Cada estrofa forma un párrafo y los versos están separados por puntos. Tras cada una de las estrofas (incluso tras la inicial) encontramos la palabra «El», que llama al estribillo (como tal debía de repetirse la primera estrofa, o quizás sólo su primer verso) indicando claramente que se trata de un poema destinado al canto.

Como era de esperar, en $Q$ faltan un buen número de estrofas que sí que están en $C$; en concreto, hay varias lagunas que abarcan series enteras (estrs. 10-14, 16-23, 28-32, 34-35). Pero, a su vez, encontramos en este testimonio estrofas ausentes de la versión más antigua y cabal del poema $(4-5,9,15,24-25)$, incluida una que parece resultado de sintetizar formulaciones de aquí y de allá y que cubre de alguna manera la laguna de estrs. 18-23 (véase nuestra nota a estr. 24 en la edición del texto). También es de destacar que $Q$ presenta las estrofas 6-7-8 en orden distinto (7-6-8) que $C$.

Algunas lecciones de $Q$ parecen mejores que las de $C$ (véanse notas a $2 \mathrm{c}, 2 \mathrm{~d}, 8 \mathrm{c}, 9 \mathrm{c})$, bien por ser difficilior, bien por razones

\footnotetext{
${ }^{12}$ A juzgar por el prólogo, a las alturas de 1753 la quiná tenía ya una cierta antigüedad; pero, sobre esta cuestión, veánse mis observaciones en «Las endechas sefardíes sobre la destrucción del Templo y sus paralelos cristianos medievales», en The Medieval Roots of Sephardic Poetry, eds. A. DEYERMOND y H. POMEROY (Londres [en prensa]), donde discuto la problemática fecha de 1578 indicada en la última estrofa de la traducción hebrea.
} 
métricas, por coherencia de sentido o porque la de $C$ no resulta convincente.

3) Por lo que respecta al texto de $M s$, consta de dieciséis estrofas (incluida la inicial, que es sólo de dos versos, como en $Q$ ) y al final se repite otra vez la estrofa inicial. Aparece escrito a renglón seguido, cada estrofa forma un párrafo y casi siempre se señala el final de verso con un punto. Tras la mayoría de las estrofas se añade «El Bet hamicdáš» como llamada de estribillo.

El texto de $M s$ es todavía más incompleto que el de $Q$ : además de presentar las mismas lagunas de series completas de estrofas que $Q$, falta también la estrofa 26 (que está en $C$ y en $Q$ ); $M s$ presenta asimismo más lagunas menores que $Q$ (1c, 3a, 27b). Pero, por otro lado, conserva la estrofa final (37), que está en $C$ pero se omite en $Q$.

En lo que se refiere al orden de las estrofas, resulta llamativo que tanto $Q$ como $M s$ presenten la misma ordenación en las estrofas 7-6-8. Asimismo, encontramos en $M s$ la estrofa facticia que viene a cubrir la laguna de 18-23.

Estos datos muestran que $M s$ y $Q$ pertenecen a una misma familia textual (diferente de la representada por $C$ ), pero no derivan uno de otro; cosa que, por otra parte, sería difícil, dado que posiblemente $M s$ sea algo anterior a $Q$ y no resulta probable que la edición aljamiada utilizase como modelo precisamente este manuscrito, de uso privado.

$M s$ presenta algunas lecciones que parecen mejores que las de $C$, la mayoría de las veces porque lee con $Q(2 \mathrm{c}, 2 \mathrm{~d}, 6 \mathrm{~d}, 8 \mathrm{c}$, estr. 33); pero también un par de lecciones de $M s$ en la estrofa final (que no está en $Q$ ) nos parecen preferibles a las de $C$. Asimismo, $M s$ presenta alguna formulación (6b) que podría provenir de una estrofa perdida en todos los testimonios.

En consecuencia, para nuestra edición hemos tratado de reconstruir un supuesto arquetipo, siguiendo fundamentalmente el texto de $C$, no sólo por ser el más antiguo sino, sobre todo, por ser el más cabal; aunque, en las ocasiones en que nos parecía mejor la otra rama de la tradición, hemos corregido con las lecciones con $Q$ (y, en la última estrofa, con $M s$ ). Por lo que respecta a las estrofas que están en la rama de $Q$ y $M s$ pero faltan en $C$, hemos procu- 
rado insertarlas en el lugar que nos ha parecido más coherente, justificando en cada caso el porqué de la ubicación. En el aparato crítico hemos recogido las variantes significativas, prescindiendo de las meramente gráficas, como la práctica frecuente (pero no sistemática) de escribir artículo y preposición unidas en una sola palabra (dela, enel) o algunos usos gráficos de $C$ que afectan a $6 / D$, ב y 9 , como ya hemos indicado.

El sistema de transcripción utilizado es el habitual entre los sefardistas españoles ${ }^{13}$.

\section{EDICIÓN DEL TEXTO}

\section{La destrucción del Templo}

0 Bet hamicdáš honrado, iguay, cómo estás tan destruido! Bet hamicdáš querido, ¡guay, cómo estás tan derocado!

1 ¿Adónde está tu hermośura y la tu fragua de gran altura? Agora estás en bajura, en el polvo enterado.

2 Estrellas y luź eras del mundo, de silla del Dio eras segundo; agora puesto en fundo y en el profondino aḅajado.

En Q llamada al estribillo con El tras todas las estrofas, incluida la 0; en Ms llamada al estribillo con El Bet hamicdáš tras estrofas 2, 3, 6, 8, 9, 15, 24, 25, 27, 33 y 36 .

0a-b el Bet hamicdáš honrado cómo está tan despoblado $Q$, el Bet hamicdáš honrado guay cómo está tan despoblado Ms.- 0c-d falta en $Q$ y en Ms.

1a arónde $Q$; fermośura $Q .-1 b$ fargua $Q .-1$ c agora en ba jura $Q M s$.- 1d estás en suelo echado $Q$, está en el suelo echado $M s$.

2a estrella $Q$; a el mundo $Q$, en el mundo $M s$.- 2 b de la silla de el $Q$, de la sía de el $M s$.- 2c agora está en el fundo C.- 2d frofondino $C$; y atan mal arebajado $Q$, y tal mal arebajado $M s$.

${ }^{13}$ Expuesto por Iacob M. HASSÁN, «Transcripción normalizada de textos judeoespañoles», Estudios Sefardies 1 (1978) págs. 147-150. 
3 Palacio del Dio eras llamado y de los cohanim eras servido; agora tan destruido y de šu 'alim muy paseado.

4 Los cohanim que allegaban como la estrella arelunbraban; los pecados perdonaban. Agora está tan acabado.

5 Todos Yisrael haćed planto y las mujeres otro tanto por el cohén grande el santo, que por nos estaba sacreficando.

6 Por los leviyim tened dolores, que en caśa del Dio eran cantores dando loores a el que sienpre sea loado.

7 ¿Adónde están los cohanim, los que perdonaban los avonim con sus źebahim delantre el Dio enšal žado?

8 ¿Adónde están los señores de los leviyim, los cantores, que cantaban con sabores delantre el duján tan preciado?

3a en ti nuestro Dio era venido $Q$, en ti muestro rey Ms.-3b y falta en $Q y$ $M s$ - 3c tan falta en C.- 3d acompañado $Q M s$.

4-5 falta en $C$ y en $M s$.

6-8 el orden de las estrofas en $Q$ y $M$ s es 7-6-8.

6a tener $Q M$ s. $-\mathbf{6 b}$ cantadores $Q$; que se dieron en mano de matadores $M s$.6c y daban muchas loores $Q$, que en caśa de el Dio eran cantadores $M s$.- 6d siempre $Q M s$; sea alvaado [sic] $Q$, sea alabado $M s$.

7a adónde están muestros cohanim $Q$, ánde están muestros cohanim $M s$. 7b perdonaban los pecados $M s$. - 7c con los vestidos lebanim $Q M s$.- 7d el Dio el enšalžado $Q M s$.

8a cohanim tachado y corregido a mano en letra cuadrada con puntos señores en $C$; ónde están muestros señores $Q$, ánde están muestros señores $M s$.- $\mathbf{8 b}$ de falta en $Q ;$ los leviyim y cantadores $Q$, que caeron entre angustiadores $M s$.- 8c con sus loores $C$, los que cantaban con sabores $M s$. - 8d preciados $M s$. 
9 Por mal servicio que hićieron detrás de la nada anduvieron; ira de el Dio encendieron: estruición ha apregonado.

10 ¡Cómo esto nos hemos de acordar: del bien que teníamos con verdad! De civdad en civdad agora cada uno deramado.

11 En la civdad non conocíamos aquel bien que teníamos; todos Yisrael estuviéramos con la nebuá y el źebah preciado.

12 Vinieron contra nos los enemigos y mataron a nos y a nuestros hijos; hićieron corer sangre de muchos inocientes que han deramado.

13 Luego a el micdáš destruyeron, a todos los atuendos escondieron y si no se fundiera el arón ya lo hubieran rehollado.

14 Dićían con gran voź alta: - ¿Adónde es el Dio de la Caśa Santa? De él non hagamos cuenta que es mentira su nombrado.-

15 Vinieron goyim angustiadores, hićieron necamá en los señores; hajamim y meldadores por la espada fueron pasados.

9 falta en C.- 9a por tal servimiento $M s$. $-9 b$ de la nada se anduvieron $M s$. $-9 c$ necamá en ellos hićieron $M s$.-9d destruición y en apregonando $M s$.

10-14 faltan en $Q$ y en $M s$.

15 falta en C.- 15c hajamim meldadores $M s$.- 15d hueron $M s$; pasado $Q$. 
16 Luego en el micdáš entraron con sus doladiźo y se homillaron y la Caśa Santa enmundaron con sangre de puercos matados.

17 Las sus lenguas mayorgaron y en la honra del Dio hablaron y a su pueblo mataron quien matado y quien afogado.

18 Las donćellas tomaban y luegos las enmundaban y las que no les agradaban las echaban por el tejado.

19 A los señores viejos honrados, sabios homildes y entendidos, por las calles estendidos, quien matado, quien ahogados.

$20 \mathrm{~A}$ los mancebos escogidos y a la espada fueron vencidos; poníanlos tendidos para el degollío como el ganado.

21 Tomaban las criaturas del meldar, lendas feguras, feguras santas y puras; de las montañas altas las han echado.

22 De caśa en caśa andaban de los judiós y non apiadaban; a los niños degollaban en pechos de sus madres asentados.

23 A los judiós que quedaban desnudos en carnes los desteraban;

16 falta en $Q$ y $M s$.

17 falta en $Q$ y $M$ s.

18-23 faltan en $Q$ y $\mathrm{Ms}$, que en su lugar traen otra estrofa: los mancebos atán preciados / y los chicos regalados / por las calles arastados / cual matado cual destripado $Q$, los mancebos tan preciados ... etc. $M s$. 
fambreyentos los enviaban

y sin remedio ninguno han quedado.

24 ¡Cómo llevaron tales penas!: de ellos atados con cadenas y joyas y piedras buenas los goyim se las han llevado

25 La Caśa Santa querida en el fuego fue adrida; el pueblo, con mala vida, de Yerušaláyim fue desterado.

26 Desterados de vila en vila por Aragón y Castilla porque la silla de el reino la han dejado.

27 A poco a poco nos aleǰamos de los šebatim y non los veemos; grande dolor tenemos de que nos habemos apartado.

28 Nuestros pecados nos apartaron y de ellos nos aleǰaron; amargos nos dejaron y ellos han repośado.

29 De haćer el šabat nos vedaron y de los mo adim nos olvidaron

24-25 faltan en $C$.

24a talas $M s$.- 24b carenas $Q$, cadena $M s$.- 24d los goyim se las iban tomando $M s$.

25a Santa y querida $M s$.- 25d de Yerušaláyim hueron destruidos $M s$.

26 falta en $M s$.

26a llevaron en mal de villa Q.- 26b por Aragón y por Castilla Q.- 26c por-que la silla $C$, y España y Siçilla $Q .-26 d$ des banda en banda han andado $Q$.

27a mos alesimos $Q$, mos ale jimos $M s$.- 27b y no los vimos $Q$, y non los veemos falta en Ms.- 27c y muchos duelos tuvimos $Q$, y munchas dolores tuvimos Ms.27d desque mos haremos apartado $Q$, de que mos habemos apartados $M s$.

28-32 faltan en $Q$ y $M$ s. 
y del roš hodéš nos baldaron

y por observar la Ley nos han matado.

30 Agora el tiempo nos ha descaído y en poder de todos ellos hemos caído y lazos nos han metido y nuestros bienes nos han quitado.

31 Por esto lloramos, oh Dio, pues que la corona cayó por la sentencia del Dio: fue por pecados que hemos obrado.

32 Si non fuera por el Dio querido, que con piadades de nuestros castigos, ya nos hubiéramos deperdidos, memoria de nos no se hubiera hallado.

33 Estas angustias traśeras olvidaron las primeras. Esparćidos por las tieras de los goyim fuimos trespiśados.

34 Lloramos todos nos con grande lloro y con grande dolor dolorido, pues que hemos descaído y más las cabezas no hemos alzado.

35 Todos nos los hemos cavśado lo que por nos ha pasado del gran pecado que hemos obrado y con nombre del Dio nos es escapado.

36 Señor Dio, que yivo es, a nuestros pecados no mires

33 con las angustias prosteras / sí olvidamos las primeras / pues vemos tantas gueras / que escuentra nos se_han levantados $C$, estas angustias / hićieron olvidar las primeras / espartidas por las tieras / de los goyim fuimos trespaśados Ms.

34-35 faltan en $Q$ y $M$ s.

36a señor Dio, que vivo eres $Q$, señor grande, que viva eres $M s$.- $36 \mathbf{b}$ a muestros $Q M s$; tú no mires $Q .-36$ de este galut tú mos $Q M s$.- 36d aḅasta tanto mal que haremos pasado $Q$, abasta tanto mal lo que habemos pasado $M s$. 
y de galut nos tires

y abasta el mal que himos pasado.

37 Tú, que es Dio apiadador, no mires los pecados del dor y manda ya al rehmidor a nuestro mašíah alabado.

\section{7 falta en $Q$.}

37a tú eres Dio Ms.- 37b no mires pecados de el dor Ms.- 37c redemidor C.37d mašía ḥ tan preciado $C$; tras $37 \mathrm{~d} M$ s repite El Bet hamicdáš honrado / guay, cómo está tan desoblado [sic].

\section{Notas explicativas}

0a Bet hamicdáš: lit. 'casa del santuario', apelativo habitual del Templo de Jerusalén; honrado: aquí 'venerado'.

0b La exclamación de dolor guay (aquí y en 0d) es tópica en la poesía luctuosa; con exclamaciones de dolor se inician también Lamentaciones 1.1. y 2.1.

0d derocado: 'arruinado, caído por tierra'.

1b fragua: 'construcción, fábrica' arquitectónica. Se inicia el poema oponiendo la antigua elevación (aquí física, en 2a-b moral) del Templo y su estado actual de abatimiento (1c-d y 2c-d), con procedimiento idéntico al de Lamentaciones 1.1, 2.1 y 4.1.

1d enterado: 'enterrado, sepultado'. La lección de $C$ posee mayor expresividad poética, frente a las más triviales de $Q$ y $M s$.

2a Porque esclarecía al mundo entero.

2b silla: 'trono', aquí refiriéndose a aquel en que se asienta la divinidad (pero véase más abajo 26c-d); lo que quiere decir es que sólo el mismísimo trono de Dios aventajaba en grandeza y esplendor al Templo.

2c fundo: 'hondo, profundidad'. Escogemos la lección de $Q$ y $M s$ por menos trivial. La forma fundo (frente a la también posible fondo) viene apoyada, además de por las rimas anteriores, por la vocalización de $C$.

2d profondino: 'lo profundo, lo más hondo'; aquí $Q$ y $M s$ presentan una lección que nos parece más trivial. 
3a Mantenemos la lección de $C$ entendiendo la rima como silábica en $d o$ (hay otros casos de rima silábica en estrs. 10, 19, 27 y $29)$; la variante de $Q$ podría explicarse precisamente por un intento de regularizar la rima como consonante en -ido (con verso de vuelta en -ado); de la accidentada transmisión del verso es buen indicativo que la palabra de rima falte en $M s$.

3b Los cohanim eran los sacerdotes de más alto rango que atendían al servicio del Templo, a quienes correspondía, entre otras cosas, ofrecer los sacrificios.

3d šu 'alim: heb. 'zorros'. Donde antes se ofrecían sacrificios de animales puros, ahora pasean las alimañas; pero que las alimañas sean precisamente zorros es eco de un motivo de Lamentaciones 5.18 .

4a allegaban: 'traían, acercaban' parece haber tenido en judeoespañol la acepción específica de 'ofrecer sacrificios'; cfr. «y ahí lo serviremos [a Dios] / corbanot allegaremos» en las coplas morales de Los extremos de la vida (E. Romero, Coplas sefardíes..., págs. 141-146: pág. 146)

4b 'relucían como una estrella', es expresión ponderativa de su esplendor moral y físico, este último debido a que iban revestidos de ricos ornamentos. El esplendor de los grandes de Israel aparece, por ejemplo, en Lamentaciones 4.7.

4c Porque los sacrificios que ofrecían servían para que Dios perdonase los pecados cometidos por el pueblo judío. Es motivo que aparece en otras quinot; por ejemplo en El Horbán de Sión: «Viendo el Dio tantos 'avonot ['pecados'] / de 'abodá źará ['idolatría'] y de ir con źonot ['prostitutas'] / todo se perdonaba con los corbanot ['sacrificios'], / el corbán del tamid ['sacrificio perpetuo'] que haćían en Ŝiyón» (según I. M. HASSÁN y E. ROMERO, «Quinot...», pág. 20).

5a-b La invitación a unirse al planto -con especial mención de las mujeres, a quienes tradicionalmente les correspondía en especial la misión de plañir- es tópico luctuoso. Obsérvese la concordancia en plural de todos con Yisrael, entendido como colectivo.

5c el cohén grande es el calco del heb. כהן הגדול 'sumo sacerdote' del Templo. 
5d Porque ofrecía sacrificios en nombre de todo el pueblo. La vocalización obliga a la lectura sacreficando, en vez de la también posible sacrificando. Nótese la terminación en -ando, que supone una licencia con respecto a la rima de vuelta general en ado.

6a leviyim: los 'levitas' o descendientes de la tribu de Leví, a quienes correspondía ejercer de sacerdotes en el judaísmo antiguo (los cohanim de 3 b y $4 a$ eran un grupo específico entre los levitas). Aquí se los menciona como una segunda clase de sacerdotes, que se encargaban, entre otras cosas, del canto y la música de los oficios sagrados $(6 b, 8 b-c)$.

6b-c En este conflictivo pasaje preferimos las lecciones de $C$ y $Q$ porque están atestiguadas por dos ramas de la tradición, son más coherentes desde el punto de vista sintáctico y mantienen el paralelismo con las que traen los mismos $C$ y $Q$ para la estrofa 8 , paralela a ésta.

En 6c elegimos la lección de $C$ porque la formulación de $Q$ parece un ripio, producto de la adición para regularizar métricamente el verso; su aparente defectividad en $C$ podría suplirse en el canto alargando las sílabas, cosa muy frecuente en el canto oriental, muy melismático; por otra parte, no es este el único caso en que $C$ presenta un tercer verso más corto, como si tendiera a estrofas de pie quebrado (véanse notas a 7c y 26c-d).

Sin embargo, las lecciones de $M s$ presentan un lenguaje muy castizo (se dieron en mano de en $6 \mathrm{~b}$, caeron entre angustiadores en $8 \mathrm{~b})$; y, por otra parte, la variante de $6 \mathrm{~b}$, el desplazamiento de b hacia c y la variante de $8 \mathrm{~b}$ mantienen en $M s$ el paralelismo entre las estrofas 6 y 8 , aunque con elementos algo distintos de las de $C$ y $Q$ : se alude a los levitas (6a, 8a), que cayeron en manos de los enemigos $(6 b, 8 b)$ y se recuerda que cantaban en el Templo (6c, $8 c$ ). Todo apunta a que en una rama de la tradición (representada por $M s$ ) se han reformulado las estrs. 6 y 8 , quizás al haberse producido en $6 \mathrm{~b}$ una contaminación con un verso de alguna estrofa perdida; la formulación de 8 b en $M s$ podría ser a su vez eco de $15 \mathrm{a}$.

6d loado: 'alabado', que es la lección que traen $Q$ y $M s$. Naturalmente, se trata de una perífrasis para referirse a Dios.

7a Vuelve a insistir en el tópico luctuoso ¿ $A d o$ ?. En $Q$ y $M s$ el orden de las estrofas es 7-6-8, lo cual implica otra ordenación lógi- 
ca: primero se menciona un estamento sacerdotal (los cohanim) y luego se hace la pregunta retórica sobre dónde fueron a parar (estr. 7); después se menciona el otro estamento (los leviyim en estr. 6) y se introduce una pregunta retórica sobre ellos (estr. 8).

7b avonim: heb. 'pecados' debería ser avonot, ya que la palabra es femenina en hebreo; pero la terminación de plural masculino en -im debe de estar atraída por la rima, y quizás precisamente esa anomalía morfológica haya producido en $M s$ la variante pecados que, al traducir el hebraísmo, mantiene el masculino, pero rompe la rima. Repite las mismas ideas que en 4c.

7c źebahim: heb. 'sacrificios, ofrendas'; para la medida del verso, veáse n. a $6 \mathrm{c}$. La variante de $Q$ y $M s$ con los vestidos lebanim ('blancos') alude a la vestidura blanca con que se cubrían los servidores del Templo.

7d enšalžado: 'alabado'. Leemos enšalžado siguiendo a $Q$ y $M s$; pero en $C$ podría leerse también ensalzado, ya que este testimonio utiliza la letra hebrea $\boldsymbol{v}$ indistintamente para la prepalatal fricativa sorda y la sibilante sorda, como es habitual en el sistema gráfico del siglo XVIII.

8a Sólo $C$ presenta aquí la lectura Adónde están los cohanim, evidente contagio de 7a que rompe la rima, y que en el ejemplar de Etz Hayim está corregido a mano al margen señores, con letra cuadrada también vocalizada.

8b $Q$ omite $d e$, pero escogemos la lección de $C$ porque la construcción el señor de (o los señores de, como aquí) para 'el señor...' es usual en judeoespañol en expresiones de respeto (por ejemplo, se antepone a los nombres de patriarcas y profetas: el señor de $Y a$ 'acob o el señor de Abraham). Para la variante de $M s$, véase nota a $6 \mathrm{~b}-\mathrm{c}$ más arriba.

8c con sabores: 'placenteramente'. Escogemos la lección de $Q$ (y $M s$ ) por lo castizo de la expresión y porque la formulación de $C$ parece mera repetición mecánica de $6 \mathrm{c}$.

8d duján: heb. 'estrado, tablado, tribuna', se refiere aquí específicamente al lugar del Templo donde cantaban los levitas mientras se ofrecían los sacrificios; preciado: 'estimado, precioso, excelente', califica en $C$ y $Q$ al duján, mientras que la variante preciados de $M s$ concuerda con los leviyim. 
9a El servicio debe de ser el que prestaban en el Templo, y lo que querría decir es que inflamaron la cólera divina (9c), seguramente por haber realizado el servicio religioso inadecuadamente y sin cumplir con las prescripciones debidas.

9b detrás de la nada anduvieron 'anduvieron tras vanidades, fueron tras cosas vanas', calca una expresión hebrea que aparece, por ejemplo, en Jeremías 2.5: «i anduuieron tras de la nada i nadearon» (según el ladino de los libros proféticos de la Biblia de Salónica, 1568: véase Haim V. SÉPHIHA, «Caracterización del ladino de la Biblia de Ferrara», en Introducción a la Biblia de Ferrara. Actas del Simposio Internacional..., ed. I. M. HASSÁN [Madrid 1994] pág. 300).

9c Escogemos la lección de $Q$, cuyo sentido resulta más coherente; la de $M s$, aunque en principio parece difficilior y por tanto preferible, puede haber resultado del contagio con $15 \mathrm{~b}$ para suplir un verso olvidado.

9d Es Dios quien ha apregonado (lit 'pregonado', aquí en el sentido de 'publicado, promulgado') la estruición ('destrucción, ruina') del Templo y de la propia soberanía judía.

10a-b En con verdad extraña el régimen preposicional: podría ser sinónimo de en verdad ('verdaderamente') o querer decir 'cuando [estábamos] con la verdad' refiriéndose al tiempo en que cumplían los preceptos. En todo caso, expresa la añoranza por el

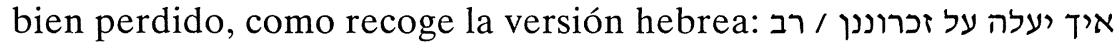
אcómo vendrá a nuestros recuerdos / el gran bien que teníamos!'; la idea se repite paralelamente en 11a-b. Nótese que acordar rompe la rima silábica en -dad.

10d cada uno: 'cada cual'; deramado: 'disperso'. Alude a la diáspora del pueblo judío, consecuencia de la destrucción del Templo.

11a la civdad por antonomasia es Jerusalén; non conocíamos: 'no nos dábamos cuenta'.

11c Podría entenderse 'ójala todo Israel hubierámos estado con...' o '[si nos hubiéramos dado cuenta del bien que teníamos] hubiéramos mantenido...'. La versión hebrea apunta a la primera interpretación: בני ישראל אנחנו / זבח ונכואה מגן אם נואלנו 'nosotros, los hijos de Israel, / ójalá nos hubiéramos servido de la nebuá y el źebah como escudo' (véase la nota siguiente). En el texto judeoes- 
pañol, nótese de nuevo la concordancia en plural con el sustantivo singular Yisrael, por referirse a un colectivo (cfr. 5a).

11d nebuá: heb. 'profecía'; źébah: heb. 'sacrificio, ofrenda'.

12 Comienza aquí la parte descriptiva del poema, con la narración de la profanación y destrucción del Templo y la matanza de la población inocente, que es motivo recurrente en Lamentaciones. La rima estrófica es aquí en -os.

13a micdáš: heb. 'santuario' del Templo. Nótese el régimen preposicional, con $a$ ante complemento directo de cosa. El sujeto son los enemigos de 12a. La profanación y saqueo del santuario se describe en parecidos términos en Lamentaciones 1.10 .

13b atuendos: lit. 'utensilios, recipientes', en la versión hebrea son כלי הקדש ('utensilios sagrados') y se refiere en concreto a los vasos, lámparas y otros objetos que se utilizaban en el culto del Templo. Se supone que los escondieron tras saquearlos; la versión hebrea trae טמנו 'profanaron'.

13c arón: heb. lit. 'armario', se refiere aquí al arca de la Alianza, que contenía las tablas de la Ley y que se conservaba en el sancta sanctorum del Templo; se fundiera podría ser 'se derritiera', cosa coherente con los hechos, ya que en las dos destrucciones de Jerusalén los enemigos prendieron fuego al Templo y, en el caso de la segunda, Flavio Josefo (Guerras de los judios, libro VII) narra cómo el fuego hizo que se fundiesen la plata y el oro de las puertas; pero parece que se entendió como 'se hundiera (en tierra), se

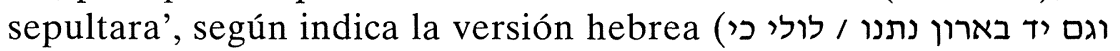
I si no hubiera sido devorado bajo tierra'), lo cual apunta a la leyenda de un milagro: el arca se habría autosepultado para evitar su profanación. No hemos podido documentar exactamente esta leyenda, aunque varios midrašim desarrollan la idea de que, tras la destrucción del Templo, los utensilios sagrados fueron puestos a salvo por los ángeles, quienes los transportaron a un monte donde Jeremías los ocultó en una cueva; también se dice que las puertas del Templo se hundieron en tierra para evitar ser profanadas; véase Louis GinZBERG, The Legends of the Jews, 7 vols. (Filadelfia 1946-47): vol. IV (1947) págs. 320-321 y referencias en vol. VI (1946) págs. 410-411.

13d rehollado: 'hollado, pisoteado'. 
14b Caśa Santa traduce el heb. bet hamicdáš (cfr. estr. 0). La pregunta de los enemigos es irónica.

$14 \mathbf{c}$ 'no lo tomemos en cuenta, no le concedamos valor, no lo estimemos en nada'. La arrogancia de los enemigos es motivo que aparece también en Lamentaciones 2.15-16 y 3.46.

14d su nombrado: quizás 'su nombre', ya que uno de los apelativos de Dios es precisamente השם ('el nombre'). Aunque E. ROMERo, Coplas sefardíes..., pág. 95 entiende 'fama'.

15a goyim: heb. 'gentiles, no judíos'; angustiadores: lit. 'que causan angustia', es término usual en textos ladinados (y, en concreto, en traducciones de la Biblia) para referirse a 'opresores, enemigos', ya que calca el hebreo צורר 'enemigo', construido sobre la misma raíz que צרה 'angustia'; a partir de ahí tomó carta de naturaleza en judeoespañol, donde se aplica frecuentemente a los enemigos destacados de los judíos: el angustiador por antonomasia es Hamán, el ministro de Asuero que pretendió el exterminio del pueblo hebreo; por extensión, también se ha llamado así modernamente a Hitler; en la quiná de La madre que se comió a su hijo, editada por I. M. HASSÁN y E. ROMERO, «Quinot...», pág. 36, se aplica, como aquí, a los invasores de Jerusalén: «entraron en la civdad angustiadores como arena de la mar».

Incluimos esta estrofa (que falta en $C$ ) aquí y no en otro lugar (como tras su paralela la estrofa 12, donde también sería posible) porque entendemos que las estrs. 12-14 y las 15-17 forman dos series paralelas, en cada una de las cuales se desarrollan por el mismo orden idénticos motivos: la llegada de los enemigos (12a, $15 a)$, que masacran a la población (12b-d, 15b-d), entran en el Templo para profanarlo y destruirlo $(13,16)$ y blasfeman contra Dios (14a-d, 17a-b).

15b necamá: heb. 'venganza'. Puntuamos entendiendo que señores se refiere a todos los varones de respeto de Israel; también podría entenderse referido a los hajamim y meldadores de $15 \mathrm{c}$, y entonces habría encabalgamiento entre b y c.

15c hajamim: heb. lit. 'sabios', se aplica a los doctores de la Ley; meldadores serían los mismos hajamim, cuya misión principal era meldar (es decir, leer, meditar y comentar la Ley).

16b doladizo: 'ídolo'; homillaron: 'inclinaron, postraron' en señal de adoración; con el mismo sentido $-\mathrm{y}$ en contextos en que 
también se trata de inclinarse ante un doladizo- aparece en otras quinot : «si es que te homillas a el doladiźo ternás folgura» (Los siete hijos de Haná, según la edición de I. M. HAssÁn y E. RoMERO, «Quinot...», pág. 44) y «Te echaré mi anillo / que digan: -Ya se humilló» (Haná y sus siete hijos, en P. DíAZ-MAS, Temas y tópicos..., pág. 207). La profanación del Templo se produjo, pues, no sólo por la entrada de gentiles, que pisaron en él y saquearon sus tesoros, sino porque los invasores instalaron allí a su falso dios. En sus, nótese el posesivo plural para varios poseedores, aunque sea una sola cosa poseída.

16c En enmundaron (lit. 'ensuciaron, hicieron inmunda') respetamos la vocalización indicada por la puntuación del texto aljamiado.

16d El colmo de la profanación es sacrificar cerdos (animales impuros) en el mismo lugar donde se ofrecían antes sacrificios de animales puros, gratos a Dios. Idéntico motivo aparece en la quiná del Horbán de Sión, aunque allí son los propios judíos los que cometen la profanación: «y corbán de tamid ['sacrificio perpetuo'] dejaron de allegar / subieron por la cerca un haźir ['cerdo'] en su lugar» (I. M. HASSÁN y E. ROMERO, «Quinot...», pág. 20).

17a mayorgaron: aquí 'ensoberbecieron, jactaron', calcando el sentido del hebreo להחגדל 'enorgullecerse, jactarse, ensoberbecerse', de la misma raíz que גדול ולעול למדר 'grande'. La versión hebrea trae ולשוגק גדולות מדברת 'y su lengua habla fanfarronadas', donde el sujeto es la lengua; en nuestro texto, sin embargo, no queda claro si el sujeto son las sus lenguas ('las lenguas [de los enemigos] se ensoberbecieron') o los enemigos implícitos ('[los enemigos] ensoberbecieron sus lenguas'), que por otra parte ejercen como sujeto en todas las demás estrofas de la 12 a la 18 y de la 20 a la 23.

17b En hablaron en puede haber cierta influencia del régimen preposicional hebreo דבר ב־ (lit. 'hablar en...') para 'hablar de' y también 'hablar contra'. Lo que quiere decir es que hablaron para deshonrar a Dios, que blasfemaron, como en la estrofa 14.

17d quien... quien: 'unos... otros'; matado: aquí 'asesinado, muerto por muerte violenta'; afogado es tanto 'ahogado (en agua)' como 'asfixiado'; aunque la versión hebrea interpreta que el ahogamiento es en agua (בחרב במים מות מהרת 'se apresura la muerte en la espada y en el agua'), lo más probable es que en principio la distinción apunte a dos tipos de muerte: por heridas con armas y 
por ahorcamiento, quizás por eco de Lamentaciones 5.12, que la Biblia de Ferrara traduce como «señores con su mano fueron ahorcados, fazes de viejos no fueron afermosiguadas». Véase nota a v. 19d.

18a A partir de aquí se desarrolla la descripción de la masacre de la población, enumerada por estamentos, que constituye un tópico en la retórica de la descripción de la destrucción de la ciudad. Ideas parecidas encontramos en Lamentaciones (aunque allí no hilvanadas en una enumeración tan sistemática, salvo quizás en 5.11-13), en la descripción de la toma de Jerusalén por Flavio Josefo y en los midrašim sobre el tema (véase, por ejemplo, Elena ROMERO, La Ley en la leyenda. Relatos de tema bíblico en las fuentes hebreas [Madrid 1989] págs. 522 y 524-525) y lo recogen otros poemas sobre la destrucción de la Ciudad Santa, tanto en la tradición sefardí como en la hispánica medieval (véanse mis artículos citados en notas 12 y 17). La enumeración de nuestro poema, empezando por las doncellas, para luego seguir con los sabios de la Ley (estr. 19), los jóvenes (20), los niños de la escuela (21) y los niños de pecho (22), sigue (aunque amplificándolo) el modelo de Lamentaciones 5.11-13.

18b enmundaban: 'ensuciaban', eufemismo por 'violaban', según confirma en la versión hebrea טמאום נשכבו ('las poseyeron deshonrosamente'). Es motivo que aparece, por ejemplo, en Lamentaciones 5.11.

18d tejado también podría leerse techado, ya que de ambas maneras puede interpretarse la grafía $\bar{\lambda}$ del texto aljamiado. Se entiende que las arrojaban desde lo alto de los tejados para que se matasen.

19a-b Los señores viejos y sabios son los mismos hajamim mencionados en $15 \mathrm{c}$; la vocalización del texto aljamiado obliga a la lectura homildes; entendidos: 'conocedores, sabios'. Se resaltan las dos virtudes esenciales del sabio (en las que insisten con frecuencia las fuentes rabínicas): la humildad y la ciencia. Los ancianos se mencionan tras las doncellas en Lamentaciones 5.12.

19c estendidos: aquí 'tendidos, echados, tirados'.

19d Parece evidente contagio de $17 \mathrm{~d}$ (o viceversa), pero no podemos proponer otra lección porque tanto la estrofa 17 como esta 
19 faltan en $Q$ y $M s$. La forma plural ahogados, por otra parte, debe de ser concordancia ad sensum, atraída además por la rima silábica en -dos de los versos precedentes.

20a mancebos: 'mozos, jóvenes solteros'; escogidos: 'selectos, los mejores'. Los jóvenes y muchachos aparecen en Lamentaciones 5.13, aunque lo que se dice de ellos es que les obligaban a hacer trabajos duros y propios de esclavos, como moler o acarrear leña. Nótese el insólito uso de preposición $a$ ante complemento directo de persona.

20b $y$ sería pleonástico.

20c-d tendidos: 'echados' en el suelo, para ser degollados como corderos. El motivo del justo sacrificado como oveja llevada al matadero se formula en Isaías 53.7, a partir de donde se convierte en tópico.

21a-c Entendemos que lenáas figuras (con vocalización determinada por la puntuación vocálica) es apelativo de las criaturas del meldar ('los niños de escuela'), con encabalgamiento entre los versos, y lo que quiere decir es: 'tomaban a los niños de la escuela, de caras (feguras) hermosas, piadosas e inocentes...'. Pero también podría entenderse que lendas feguras es lo que meldaban las criaturas, y entonces los versos significarían: 'tomaban a los niños [quitándolos de] leer textos hermosos, piadosos y buenos...'.

22a-b Puntuamos con encabalgamiento ('[los enemigos] iban de casa en casa de los judíos y no se apiadaban'); pero podría entenderse como oraciones separadas y entonces en b habría un $y$ pleonástico: '[los enemigos] iban de casa en casa; no se apiadaban de los judíos'.

22d asentados: 'sentados'. Los niños de pecho en brazos de sus madres se mencionan en Lamentaciones 2.11-12 y 2.20, pero para ponderar el hambre que pasan hijos y madres durante el asedio de Jerusalén.

23b desnudos en carnes : 'despojados, sin abrigo'.

23c fambreyentos: 'hambrientos'.

23d remedio: 'recurso, auxilio, refugio'.

24 Introducimos aquí esta estrofa y la siguiente (que faltan en $C)$ porque enlaza perfectamente con la mención de los desterrados de estr. 23 (que sólo está en $C$ ) y en $Q$ preceden a la 26 (que está en $C$ y en $Q$ ). El estado de sometimiento del pueblo judío se re- 
salta por el contraste entre las joyas que los enemigos se apropian y las cadenas con que cargan a sus prisioneros; la oposición entre el enemigo triunfante y el pueblo judío sometido es motivo insistente en Lamentaciones (véase, por ejemplo, 1.5).

Prescindimos, sin embargo, en nuestra edición de la estrofa que precede a estas dos en $Q$ y $M s$ («Los mancebos atán preciados / y los chicos regalados, / por las calles arastados, / cual matado, cual destripado»), que viene a salvar la laguna de estrs. 19-23 y parece una síntesis de ideas y formulaciones provenientes de otras estrofas ausentes en $Q$ y $M s$ : el v. $a$ podría ser eco de la mención de los mancebos en $20 \mathrm{a}$ y repite el adjetivo preciado, recurrente en el poema en posición de rima (8d, $11 \mathrm{~d}$, variante de $37 \mathrm{~d}$ ); el v. $b$ recoge la mención de los niños de 21a; el $c$ es eco de 19c; y $d$ calca la construcción quien...quien... ado de $17 \mathrm{~d}$ y $19 \mathrm{~d}$.

25b adrida: 'ardida'; quiere decir que prendieron fuego al Templo.

25d Yerušaláyim es, naturalmente, el nombre hebreo de Jerusalén. El destierro es motivo que aparece en Lamentaciones y tema fundamental de Jeremías.

26a vila: 'villa', supondría una licencia de la rima consonante en -illa. La variante de $Q$ respeta la rima, pero es menos coherente desde el punto de vista sintáctico.

26b Menciona los topónimos como destinos del destierro; pero dado que en Tiš'á beab los judíos sefardíes conmemoraban también la expulsión de los reinos hispánicos, tal mención supone una alusión implícita a esa segunda diáspora.

26c-d la silla ('el trono') representa aquí la soberanía nacional, perdida por la invasión de los gentiles y la destrucción del Templo. Escogemos la lección de $C$ porque aunque -como en otros casostiende a los versos de pie quebrado, la de $Q$ nos parece más trivial, al omitir la alusión a la pérdida de la soberanía en beneficio de una amplificatio en la enumeración de topónimos.

26d Escogemos la lección de $C$ porque es coherente con el verso anterior, pero la expresión de banda en banda que aparece en $Q$ es muy castiza.

27a alejamos obliga a entender la rima estrófica como silábica en -mos. 
27b šebatim: heb. 'tribus', conserva el género masculino que tiene en hebreo, como muestra el artículo los y el consecuente ellos en 28b. Quiere decir que la toma de Jerusalén por los gentiles provocó la dispersión de las tribus de Israel. El verso es hipermétrico, pero aparece casi con la misma formulación en $Q$, mientras que en Ms la omisión del final lo deja hipométrico.

27d apartado: 'separado' (como apartaron en 28a); de que (en $C$ y en $M s$ ) sería 'porque, a causa de que', pero $Q$ presenta la variante desque ('desde que, desde el momento en que').

28a Se incide en una idea tópica en la moral judía (y, a partir de ella, también en la cristiana): que los males que suceden son consecuencia de los pecados cometidos. Se repite casi de forma obsesiva en Lamentaciones (1.8, 1.18, 3.42, 4.13, 5.17, etc).

28b El antecedente de ellos es los šebatim de 27b. Pero en 28d ellos son los enemigos.

28c amargos: 'tristes, afligidos'.

28d han reposado: 'se han quedado tranquilos, se han quedado descansados'.

29a nos vedaron: 'nos prohibieron'. Se enumeran a continuación los impedimentos para la práctica de su religión que tuvieron que padecer los judíos desterrados en tierras de gentiles, el primero de los cuales es la interdicción de observar el šabat. La imposibilidad de celebrar fiestas y sábados está en Lamentaciones 2.6. Nótese que la rima estrófica es silábica ampliada en -daron.

29b mo 'adim: 'sacrificios' y también 'festividades religiosas' en general; nos olvidaron: entiéndase 'nos hicieron olvidar'.

29c roš hodéš es la celebración del novilunio, que marca el inicio de cada mes judío; baldaron: 'abolieron, abrogaron'.

29d La Ley: la Torá y, en general, la religión judía, con todos sus preceptos y prescripciones.

30a descaer puede ser tanto 'decaer' como 'perder el honor y la consideración' o 'vencer un plazo'. Por tanto, el sentido de la frase podría ser 'ahora es tiempo de decadencia para nosotros' (que es como parece haberlo entendido la versión hebrea al traducir נפלנו 'caímos'); o bien: 'ahora el tiempo nos ha hecho perder el honor y la consideración [que teníamos]'; o todavía: 'ahora nos ha vencido el plazo [para pagar nuestras culpas]', idea acorde con la insis- 
tencia en la desdicha como castigo a los pecados. Véase también nota a $34 \mathrm{c}$.

30b ellos serían otra vez los goyim o gentiles opresores del pueblo judío.

30c lazos ('ataduras, ligaduras') son los del cautiverio y el sometimiento a los gentiles, como las cadenas de $24 \mathrm{~b}$.

31b corona: se refiere a la soberanía nacional -como corrobora en la versión hebrea עטרת מלכנו 'la corona de nuestro reino'-, recogiendo casi literalmente la idea de Lamentaciones 5.16, que la Biblia de Ferrara traduce como «cayó corona de nuestra cabeça».

31c-d Insiste en que lo sucedido es por causa de los pecados cometidos: de ahí que la pérdida de la soberanía sea consecuencia de una sentencia condenatoria de Dios.

32a-b Parece faltar un verbo, aunque se entiende el sentido: Dios se ha apiadado de su pueblo después de haberlo castigado, como corrobora una vez más la traducción hebrea הוגה ורחם ליסרנו 'porque se apenó y se apiadó de nuestros tormentos'.

32c-d Subyace una idea fundamental del judaísmo: que Dios puede castigar a su pueblo, pero siempre lo preservará de la aniquilación; algo parecido en Lamentaciones 3.31-32. En deperdidos nótese la concordancia en plural del participio en la forma verbal compuesta.

33a traśeras: 'últimas', especialmente el último elemento de una serie. En esta estrofa escogemos la formulación atestiguada en $Q$ (y, con variantes, en $M s$ ) porque trae lecciones más difíciles y documentadas como léxico castizo en judeoespañol (traśeras, esparcidos, trespiśados, o el mismo sentido de olvidar), mientras que $C$ parece más trivial.

33b olvidaron: aquí 'hicieron olvidar'.

33c esparcidos: 'dispersos'. Las tieras son las de la diáspora.

33d trespiśados: 'pisoteados (moralmente), humillados'.

34a lloro rompe la rima estrófica en -ido; la respetaría la expresión casi sinónima con gran gemido.

34c Para descaído véase nota a 30a: aquí ha de estar en una de las dos primeras acepciones.

34d levantar cabeza tiene también en español actual el sentido metafórico de 'recuperarse tras una adversidad'. 
35a Nótense las nuevas concordancias en plural de todos y los, seguramente atraídas por el plural de nos y el sustantivo plural implícito males o dolores.

35b 'lo que nos ha sucedido'.

35d nos es escapado: 'somos liberados de ello'. Es la única estrofa en que la rima de los vv. a-c coincide exactamente con la del verso de vuelta.

36a Como suele ser habitual en las coplas sefardíes, se acaba con una o varias estrofas en que se invoca el nombre de Dios, se pide clemencia para el pueblo y se hacen votos por la redención. El mismo final tópico está ya en Lamentaciones 5.

36b 'no atiendas a nuestros pecados, no tengas en cuenta nuestros pecados'.

36c galut: heb. 'destierro', se refiere por antonomasia a la diáspora judía tras la destrucción del Templo; nos tires: 'nos saques'.

36d Vocalizamos himos (y no hemos) guiándonos por la puntuación de $C$; en $M s$ es habemos y en $Q$ haremos, con errata.

37a apiadador: 'que se apiada, piadoso'.

37b no mires: 'no atiendas a, no tengas en cuenta', como en 36b; dor: heb. 'generación' y también 'época' y 'siglo'.

37c rehmidor: 'redentor', es el mismo mašíah del verso siguiente. Escogemos la lección de $M s$ porque es forma castiza en judeoespañol.

37d mašíah: 'mesías'. Es tópico en las coplas sefardíes que las estrofas finales deseen la llegada del mesías y la restauración del Templo y de la soberanía nacional. De nuevo preferimos la lección de $M s$ porque la de $C$ nos parece más trivial, posible repetición mecánica de una formulación recurrente en el poema (cfr. 8a, 11d).

\section{COMENTARIO}

\subsection{El proceso de transmisión de La destrucción del Templo}

Hemos dicho que en nuestra edición tomamos como base el texto de $C$, con algunas lecturas de $Q$ y (en la última estrofa) de $M s$. De todas formas, no podemos perder de vista una circunstancia que dificulta cualquier intento de constitución del texto de La destrucción del Templo: nos las habemos con un poema que no sólo ha vivido una historia de transmisión escrita, sino también oral. 
Como todas las coplas sefardíes, se trata de poesía destinada al canto: lo corroboran testimonios externos (incluido el del prólogo hebreo de $C$, que alude a cómo se decía en la sinagoga) y algunos rasgos internos, como las llamadas al estribillo, que no tienen sentido más que si el poema se concebía para cantar.

Las coplas a veces se cantaban teniendo delante un texto escrito (manuscrito o impreso) y sin duda esa es la función que tuvieron los testimonios que han llegado hasta nosotros: las versiones impresas $C$ y $Q$ se nos han conservado en dos de los típicos libritos de pocas páginas y por lo general bajo precio que se ponían a la venta con motivo de las distintas festividades judías (en este caso, de Tiš'á beab) precisamente para que los fieles los leyesen y cantasen las coplas contenidas en ellos; y para recordarlas y cantarlas debió de copiar Semuel Alhadef su colección de quinot en hebreo, ladinadas y en judeoespañol.

A la recíproca, las coplas también se aprendían de memoria, a fuerza de oirlas cantar, y a partir de un soporte tan lábil como la memoria podían volver a ponerse por escrito, en manuscritos que a veces se destinaron sólo al uso personal, mientras que otras acabaron sirviendo de modelo a impresores. Por tanto, en cualquier texto de coplas sefardíes podemos encontrar variantes difícilmente explicables recurriendo al repertorio de posibles errores que afectan a la copia de un texto escrito, pero que se entienden fácilmente como producto de la recreación continua a la que se ven sometidos los textos en un proceso de transmisión oral.

Por poner algunos ejemplos, para que se produjese en una copia escrita una reestructuración del paralelismo como la que se da en las estrs. 6 y 8 (véase nota a 6b-c) haría falta una intervención muy deliberada del copista, pero en la transmisión oral ese es un fenómeno que se da espontáneamente con bastante frecuencia. Sería también muy difícil que una estrofa como la que en $Q$ y $M s$ sustituye a la larga serie perdida de estrs. $18-23$ se produjese en un proceso de transmisión escrita (véase nota a estr. 24), pero es perfectamente verosímil que una síntesis de ideas y de formulaciones como esa resulte de un proceso de oralidad (y en atención a ello no la hemos considerado en nuestra edición como una estrofa más, sino como una estrofa facticia que sintetiza toda una serie), ya que ese tipo de reestructuraciones, consistentes en resumir drástica- 
mente las mismas ideas con formulaciones muy distintas (aunque respetando el esquema métrico) son bastante frecuentes. El romancero está lleno de ellas, por ejemplo, lo mismo que está lleno de muestras del caso contrario: amplificaciones a veces muy extensas a partir de un motivo mínimo.

$\mathrm{Y}$, para seguir en el terreno de las amplificaciones y reducciones, nuestro poema nos plantea la duda de cómo debió de ser originalmente la estrofa inicial, que se repetía como estribillo: en nuestra edición hemos elegido la lección de $C$, es decir, una estrofa de cuatro versos; pero cabe preguntarse si realmente la estrofa inicial era un tetrástrofo (y entonces $Q$ y $M s$ presentan una variante abreviada, en que la redondilla se reduce a pareado) o al revés: que la estrofa inicial fuese un pareado (como traen $Q$ y $M s$ ) y la lección de $C$ haya resultado de una amplificación paralelística.

También se explicaría por la influencia de la oralidad la recurrencia de algunas formulaciones que parecen haber emigrado de un lugar a otro del poema (véanse notas a 8 c y $37 d$ ), incluso desde una estrofa posterior a una anterior (ver nota a 8b). Esto es difícil en un proceso de copia escrita, pero perfectamente posible si el texto se tiene en la memoria.

\subsection{La métrica}

La forma métrica adoptada es muy frecuente en las coplas sefardíes: cuartetas zejelescas con rima aaav; sólo la estrofa inicial (que al parecer se usaba como estribillo) se aparta de este esquema, en $C$ porque es una redondilla $a b b a$ y en $Q$ y $M s$ porque es un pareado.

Los versos son anisosilábicos, cosa frecuente en las coplas sefardíes, y que en definitiva tiene relación con los modos musicales según los cuales se solían entonar: la interpretación musical a la manera oriental es a menudo muy melismática y permite alargar las sílabas en el canto (o incluso, a veces, obliga a ello), por lo cual el cómputo silábico acaba siendo bastante irrelevante para mantener el ritmo del poema. ${ }^{14}$

\footnotetext{
${ }^{14}$ Para la adopción de los modos y formas de interpretación de la música culta otomana por los sefardíes a partir del mismo siglo XVI hasta hoy, véase Edwin SEROUSSI, «The -Turkish Makam in the Musical Culture of the Ottoman Jews: Sources and Examples», Israel Studies in Musicology 5 (1990) págs. 43-68. Para el uso de esos mismos modos musicales en una de las coplas sefardíes más
} 
A falta de un criterio mejor, he realizado el cómputo silábico teniendo en cuenta lo habitual en la poesía castellana posterior al siglo xvi por lo que respecta a realización de sinalefas, finales agudos o esdrújulos, etc. Aunque, teniendo en cuenta las posibles pervivencias de usos medievales con respecto a la dialefa en la poesía sefardí y lo antes expuesto con respecto al tratamiento de los versos en el canto, quizás esos criterios no sean totalmente válidos para las coplas sefardíes. Según el criterio aplicado, el cómputo silábico del poema completo sería el siguiente:

[estr. 0] 7-9-7-9 / [1] 8-10-8-7 / [2] 10-9-7-9 / [3] 9-11-8-10 / [4] 89-8-9 / [5] 9-9-8-11 / [6] 10-9-5-9 / [7] 8-10-5-8 / [8] 8-9-8-9 / [9] 8-98-8 / [10] 9-10-6-10 / [11] 10-8-10-11 / [12] 10-11-10-9 / [13] 8-11-10$8 /$ [14] 8-11-7-8 / [15] 10-10-8-9 / [16] 8-10-9-9 / [17] 8-8-7-9 / [18] 7-8-9-9 / [19] 10-9-8-8 / [20] 9-9-7-11 / [21] 7-8-8-12 / [22] 7-10-8-11 / [23] 8-11-9-11 / [24] 9-9-8-9 / [25] 8-7-8-11 / [26] 9-8-5-7 / [27] 1011-7-10 / [28] 10-8-7-7 / [29] 9-11-9-12 / [30] 11-13-8-10 / [31] 8-9-8$10 /$ [32] 10-11-10-11 / [33] 8-8-8-10 / [34] 11-10-7-11 / [35] 9-8-10-12 / [36] 8-9-7-9 / [37] 7-10-8-10.

En todo caso, en nuestra quiná los versos oscilan entre las cinco y las trece sílabas, con mayoría de versos de ocho sílabas (43 del total de los 152 versos del poema, tal como lo hemos editado), seguidos de los de nueve ( 36 del total) y diez (29); hay también bastantes versos de once y de siete sílabas (18 en ambos casos), pero son muy escasos los de menos de siete (tres de cinco sílabas y sólo uno de seis); tampoco hay más que tres versos de doce sílabas y sólo uno de trece.

Pero, más que el cómputo silábico, quizás resulte relevante la tendencia -más acusada en la versión $C$ que en las otras dos más tardías- al uso del pie quebrado en el tercer verso de la estrofa: nada menos que en treinta y una de las treinta y siete estrofas zejelescas el tercer verso es más corto que el que le precede (estrs. $1,2,3,4,5,6,7,8,9,10,12,13,14,15,16,17,19,20,22,23,24,26$, $27,28,29,30,31,32,34,36$ y 37$)$, y precisamente buena parte de los versos más cortos del poema (todos los de cinco sílabas, el de seis y ocho de los de siete sílabas) son terceros versos de sus

importantes, las de Las hazañas de José, el mismo SERoussi, «La música en las Coplas de Yosef hasadic de Abraham Toledo», Sefarad 56 (1996) págs. 377-400. 
respectivas estrofas. Paralelamente, parece haber una cierta tendencia -menos acusada- a que el cuarto verso (es decir, el de vuelta) sea algo más largo que los demás: ello sucede en once de las estrofas $(3,5,11,20,21,22,25,29,31,33,35)$ y un buen porcentaje de los versos más largos (todos los de doce sílabas, ocho de once y siete de diez) está en el cuarto verso.

En cambio, el cómputo silábico en la cuarteta inicial de $C$ es 7 9-7-9; en $Q$ es un pareado octosilábico (estropeado en $M s$ por la adición de una exclamación que alarga el verso $b$ ), lo cual nos hace pensar que -matizando lo dicho más arriba- quizás el estribillo original era tetrástico alternando versos heptasílabos y eneasílabos, como en $C$. La razón para suponerlo es que la tendencia a regularizar la métrica en octosílabos es frecuente en la poesía hispánica -especialmente en la de transmisión oral, pero no sólo- y, por tanto, los octosílabos del estribillo en pareados de $Q$ y $M s$ pueden considerarse como una trivialización ${ }^{15}$. Esa tendencia regularizadora explicaría también que en las versiones más modernas haya menos versos de pie quebrado y, en general, la abundancia de octosílabos (45) en las estrofas zejelescas de todos los testimonios: es posible que parte de esos octosílabos no fueran tales en una redacción original.

Todo ello apunta a que el esquema estrófico fuese una serie de cuartetas zejelescas anisosilábicas con tendencia al pie quebrado en $c$ y quizás verso de vuelta algo más largo que los monorrimos precedentes; entre estrofa y estrofa se repetiría un estribillo de cuatro versos que alterna un verso más corto y otro más largo.

Por lo que se refiere a las rimas, la mayoría podrían entenderse como consonantes según las convenciones de la métrica hispánica; las del verso de vuelta son en -ado, con alguna licencia, por otra parte frecuente en el sistema de rimas común en las coplas sefardíes: -ando (5) y -ados $(15,16,19,22$ y 33). Sin embargo, hay algunas rimas estróficas que no pueden explicarse como consonantes, pero resultan plenamente regulares en el sistema de rimas de las

\footnotetext{
${ }^{15}$ Para la tendencia de la poesía hispánica a regularizar los versos como octosílabos, véanse nuestras observaciones -al hilo de un poema judío medieval en que esa tendencia ha actuado claramente como trivialización- en Sem Tob de Carrión, Proverbios morales, ed. de Paloma DíaZ-MAS y Carlos Mota (Madrid 1998) pág. 94 y nota 82.
} 
coplas sefardíes, en el cual-seguramente por influencia de la rima hebrea- lo que cuenta es la coincidencia de los últimos sonidos del verso (la mayor parte de las veces, la última sílaba), independientemente de dónde recaiga el acento; en ocasiones, la rima silábica puede ampliarse a uno o varios de los sonidos precedentes, que no tienen por qué ser los mismos en todos los versos que riman entre sí con la misma rima silábica. ${ }^{16}$

Tenemos varios ejemplos de rimas silábicas en nuestro poema: en estr. 3 es en - $d o$ (aunque en los vv. $b$ y $c$ se amplía en -ido, mientras que el $a$ rima simplemente en - $d o$ con sus compañeros: $Q$ regulariza los tres versos en -ido); en 7 riman todos los versos en el morfema de plural hebreo -im, aunque en los vv. $a$ y $b$ coincide la sílaba -nim; en estr. 10 encontramos las rimas cuasisilábicas dar/-dad/-dad; en estr. 11 la rima es en -amos, independientemente del acento esdrújulo; en 12 las tres palabras riman en -os; en 13 coincide la última sílaba -ron de los tres versos monorrimos, aunque dos de las palabras de rima son llanas y la tercera aguda; en 14 la rima es en -ta; en 19 encontramos rima silábica en -dos, pero en los vv. $c$ y $d$ coincide el final -tendidos; en 27 encontramos rima en -mos (ampliada a -emos en $b$ y $c$ ); 31 parece presentar rima en -ó, pero nótese que en los tres versos precede a esa vocal un elemento palatal consonántico o semiconsonántico; en 36 la rima es en -es; en 37 la coincidencia es en -dor; en cuanto a las estrofas 32 y 34 , en el único testimonio que las conserva presentan formulaciones estropeadas, aunque podemos suponer que fuese consonante en -ido.

${ }^{16}$ El uso de este tipo de rima fue ya señalado en los Proverbios morales de Sem Tob por Emilio Alarcos LloraCH, «La lengua de los Proverbios morales de don Sem Tob», Revista de Filología Española 35 (1951) págs. 249-309: págs. 262268 , quien la llama rima homoioteleuton. También la señala para otro poema judío medieval, como es la Lamentación del alma ante la muerte (resaltando que se da además en quinot sefardíes), Jesús A. CID, "Lamentación del alma ante la muerte. Nuevo poema medieval», en Estudios de Folklore y Literatura dedicados a Mercedes Díaz Roig, eds. Beatriz GARZa CuARón e Yvette JimÉnez de BÁEZ (México 1992) págs. 729-791: págs. 769-770. Específicamente para las coplas judeoespañolas lo ha tratado I. M. HASSÁN en su introducción a E. ROMERO, Coplas sefardíes..., págs. 11-13 y el mismo I. M. HASSÁN, «Un género castizo sefardí: las coplas», en Los sefardíes: Cultura y literatura, ed. P. DíAZ-MAS (San Sebastián 1987) págs. 103-123: págs. 110-112, donde aduce algunos ejemplos muy similares a los que a continuación indicamos en nuestro poema. 


\subsection{Lengua y estilo}

Por lo que se refiere al lenguaje, son de destacar algunos rasgos morfosintácticos y léxicos.

Con respecto a lo primero, llaman la atención varios casos de concordancia ad sensum en plurales: de sustantivo singular de sentido colectivo con adjetivo en plural $(5 \mathrm{a}, 11 \mathrm{c})$, de pronombre relativo en singular con participio en plural (19d) o de pronombre sujeto plural con el participio de la forma verbal compuesta también en plural (32c); incluso alguna vez se añade el morfema de plural a un adverbio por contagio de un pronombre en plural cercano (35a). Es cierto que todos los casos se dan en estrofas conservadas exclusivamente en $C$, pero su relativa abundancia nos ha llevado a no considerarlos meras erratas gráficas, sino un rasgo lingüístico, al menos característico de ese testimonio; en consecuencia, hemos mantenido esos plurales anómalos en nuestra edición.

En cuanto al léxico, nuestro poema presenta rasgos frecuentes en la coplística y en la literatura sefardí de la época clásica (s. xviII) en general: singularmente, el mantenimiento de una serie de arcaísmos hispánicos, que conviven con abundantes hebraísmos.

Arcaísmos podríamos señalar bastantes: derocado (0d), fragua en el sentido de 'construcción' (1b), planto (5a), atuendos (13b) en el sentido de 'utensilios'; quizás fundiera (13c) si de verdad está aquí en el sentido de 'hundiera' y desde luego afogado (17d) y fambreyentos (23c), feguras (21b-c) si significa 'rostros' como hemos interpretado, veemos (27b), habemos (27d), etc.

Por lo que respecta a los hebraísmos, la mayoría son préstamos crudos de la lengua hebrea (0a, 0c, 3b, 3d, 7c, 8d, 11d, 13a, 13c, $15 \mathrm{a}, 15 \mathrm{~b}, 15 \mathrm{c}, 25 \mathrm{~d}, 27 \mathrm{~b}, 29 \mathrm{c}, 36 \mathrm{c}, 37 \mathrm{~b}, 37 \mathrm{~d}$ ), aunque entre ellos hay alguno cuya forma no corresponde con la hebrea normativa y ha sido, por tanto, adaptado a las necesidades del texto (concretamente, a la rima: 7b). Otros son calcos semánticos del hebreo, que se naturalizaron en judeoespañol a partir de la lengua de las traducciones de textos bíblicos y litúrgicos: Caśa Santa (14b), angustiadores (15a), mayorgaron (17a) y quizás hablaron en (17b).

Como no es raro en los textos de la época clásica (y más si se trata de un poema litúrgico o paralitúrgico), no encontramos ningún turquismo ni préstamos de otras lenguas en contacto con la de los sefardíes, y sí en cambio algunas palabras muy característica- 
mente judeoespañolas: el Dio (2b, 3a, etc), meldar (21b) y meldadores (15c) o la forma con metátesis adrida (25b). En conjunto, la lengua de nuestro poema parece ser la característica de la época clásica, similar a la utilizada en otras coplas del siglo xviII.

Un rasgo estilístico fundamental es el paralelismo, que estructura todo el poema, hasta el punto de que la observación de cómo se distribuyen las series paralelísticas nos ha permitido deducir en nuestra edición la colocación de alguna de las estrofas ausentes de $C$ y que en la rama de la tradición representada por $Q$ y $M s$ aparecía en un lugar donde estos testimonios presentan grandes lagunas con respecto a $C$ : es el caso de la estrofa 15 , que hemos colocado precisamente allí porque entendemos que 12-13-14 forman una serie paralela a [15]-16-17.

Tanto el paralelismo como el uso de una serie de recursos propios del planto (exclamaciones, guayas, interrogación retórica «¿dónde está...?», invitación a unirse al duelo, etc.) son procedimientos comunes a toda una tradición de poesía de lamentación por las ciudades santas perdidas, no sólo en la literatura judía (en hebreo y en diversas judeolenguas, como el judeoespañol o el judeoitaliano), sino también en las literaturas románicas medievales. Pero esta es cuestión que ya he tratado en otro lugar ${ }^{17}$.

\section{RESUMEN}

En este artículo se presenta una edición crítica y detalladamente anotada de la endecha en lengua sefardí La destrucción del Templo, tomando como base los tres testimonios aljamiados en que nos ha llegado: dos libritos impresos en 1753 y ha. 1900, y un manuscrito del siglo XIX.

PALABRAS CLAVE: Literatura sefardí, endechas, aljamía, Jerusalén.

\section{SUMMARY}

The aim of this article is to offer a critical and annotated edition of the Sephardic dirge La destrucción del Templo ('the destruction of Jerusalem Jewish Temple') based on three sources written in Hebrew characters: two chapbooks printed in 1753 and $c a$. 1900, and a mauscript dated to the nineteenth century.

KEYWORDS: Sephardic Literature, dirges, aljamiado texts, Jerusalem.

\footnotetext{
${ }^{17}$ Lo analizo más detalladamente en mi artículo «Quinot sefardíes y Complants catalanes: lamentaciones por las ciudades santas perdidas», en Judaísmo Hispano. Estudios en Memoria de J. L. Lacave Riaño, ed. E. ROMERo (en prensa) y en el citado en nota 12 .
} 